\title{
LEFTWARD SPATIAL BIAS IN DIALYZED PATIENTS WITH END-STAGE RENAL DISEASE: A SIGN OF RIGHT HEMISPHERIC ATTENTIONAL ACTIVATION OR IMPAIRED LEFT-SIDED DISENGAGEMENT?
}

Aleksandra Mańkowska ${ }^{1}$, Kenneth M. Heilman ${ }^{2,3}$, John B. Williamson ${ }^{2,4}$,
Bogdan Biedunkiewicz $^{5}$, Alicja Dębska-Ślizień ${ }^{5}$, and Michał Harciarek

${ }^{1}$ Division of Neuropsychology, Institute of Psychology, Department of Social Sciences, University of Gdansk, Gdansk, Poland

${ }^{2}$ Malcom Randall VA Medical Center

${ }^{3}$ Department of Neurology, University of Florida, Gainesville, FL, USA

${ }^{4}$ Center for Obsessive Compulsive and Anxiety Related Disorder, Department of Psychiatry, University of Florida, Gainesville FL, USA

${ }^{5}$ Department of Nephrology, Transplantology and Internal Medicine, Medical University of Gdansk, Gdansk, Poland

Aleksandra MaŃKowsKa, https://orcid.org/0000-0002-5422-1541; KenNeth M. Heilman, https://orcid.org/0000-0003-0328-5892; JoHN B. WilLiamsON, https://orcid.org/0000-0001-94561797; Bogdan Biedunkiewicz, https://orcid.org/0000-0002-7715-0176; Alicja DęBSKa-Ślizień, https://orcid.org/0000-0001-8210-8063; Michal HaRCIAREK, https://orcid.org/0000-0001-8289-8878. Correspondence concerning this article should be addressed to Michal HarciareK, Uniwersytet Gdański, Wydział Nauk Społecznych, Instytut Psychologii, ul. Bażyńskiego 4, 80-309 Gdańsk, Poland; email: michal.harciarek@ug.edu.pl.

This study was supported by the National Science Center, Poland (grant number 2015/17/B/ HS6/03951), PI: Michał Harciarek. None of the funders had any role in study design, data collection, data analysis, interpretation, or the decision to submit article for publication.

The authors declare no conflicts of interest.

The manuscript was performed in part by a US Government employee.

Handling editors: Magdalena Szubielska \& Pawee StróżaK, John Paul II Catholic University of Lublin.

Received 5 May 2021. Received in revised form 29 October 2021, 4 December 2021. Accepted 17 December 2021. Published online 2 February 2022. 
In the horizontal line bisection task, patients with end-stage renal disease (ESRD) treated with dialysis typically have an increase in the normal leftward attentional bias. It is not clear, however, whether this increased bias is related to an increase of attention toward left hemispace or impaired disengagement from left-sided stimuli. Non-demented patients with ESRD who were being treated with dialysis and demographically matched healthy controls attempted to bisect series of horizontal lines composed of two segments of unequal length and width, with the longer segment placed to the right or left. To test for the presence of a global spatial attentional bias, participants attempted to find the middle of the whole line. To test for focal attentional engagement and attentional disengagement, participants were asked to bisect only the longer segment of these compound lines. For the global condition, both patients and healthy controls were biased toward the longer segment and more so to the left. In the focal condition, when the longer segment was on the right side, both groups deviated their bisections toward the shorter segment. However, when in the focal condition the longer segment was on the left healthy controls deviated their bisection significantly more rightwards than did the patients, whereas with the longer segment on the right, the patients and healthy controls did not differ in their bias. These results suggest that the previously recognized dysfunction of the right fronto-subcortical attentional network in dialyzed patients might account for the results of the current study.

Keywords: dialysis; line bisection; attentional bias; attentional disengagement; global attention; focal attention.

The brain receives more information than it can fully process. Attention is the means by which the brain triages this incoming information in order to determine if this information requires further processing. However, attention is a complex construct, and there are many forms of attention. Normally, based on our long and short-term goals, we allocate attention to important and novel stimuli. Studies of patients with cerebral lesions have revealed that attention can be object-centered (allocentric), visually (macular-retinal) centered, and head-body centered (egocentric) (for review see Heilman \& Valenstein, 2003). Hemispatial neglect is an impairment in orienting attention and/or responding to stimuli located in either left or right body-centered (egocentric) hemispace, that cannot be attributed to a primary sensory or motor defect (Heilman \& Valenstein, 1979). This phenomenon is most commonly caused by a contralesional hemispatial attentional disorder and typically results from an injury to the right parietal lobe (Bowen et al., 1999; Heilman \& Valenstein, 1979). Prior research has revealed that, whereas most often human's right hemisphere can allocate attention to both left and right hemispace, the left hemisphere primarily allocates attention to the right hemispace (Heilman \& Van Den Abell, 1980; Lynch, 1980; Robertson et al., 1988; Wright et al., 2015). Therefore, an injury to the right hemisphere is more likely to cause contralesional spatial neglect than is an injury to the left hemisphere (Heilman \& Valenstein, 1979). There are, however, some patients with right frontal-subcortical lesions who, usually after several weeks, may develop ipsilateral neglect (Harciarek et al., 2012; Kwon \& Heilman, 1991), and allocate their attention leftward. 
Patients with end-stage renal disease (ESRD), especially those receiving dialysis (Dixit et al., 2013; Mańkowska et al., 2017; Michałowski et al., 2016), often develop disorders of attention. In addition, these individuals typically have changes in cognitive functions mediated by their fronto-subcortical networks, frequently due to cerebrovascular abnormalities (Pereira et al., 2005). Further, a recent study investigating frontal attentional systems in hemodialyzed patients demonstrated that attentional problems observed in this group are relatively selective, predominantly affecting arousal/energization (Harciarek et al., 2016). In addition, it has been shown that these patients are also often unable to correctly allocate spatial attention, presenting with increased pseudoneglect (Mańkowska et al., 2017), i.e., greater leftward attentional bias than that seen in healthy controls (see Bowers \& Heilman, 1980).

The mechanism accounting for the increased leftward bias in patients receiving dialysis is not entirely known. However, there is both clinical and neuroimaging evidence that dysfunction of the right fronto-subcortical areas might lead to the disinhibition of the right parietal lobe that is responsible for allocating attention to the left (for review see Heilman \& Valenstein, 2003; Jewell \& McCourt, 2000). For example, based on the model of attention proposed by Michael Posner, if healthy adults are called upon to shift attention to another place in visual space, before engaging their attention to a novel or different stimulus, they must first disengage attention from the current stimulus (Mańkowska et al., 2019; Posner \& Petersen, 1990). According to Denny-Brown's model, the frontal lobe mediates disengagement and avoidance behaviors, whereas the posterior parietal lobe mediates engagement and approach behaviors (Denny-Brown \& Chambers, 1958; Posner, 1980). In healthy people, these areas mediating engagement and disengagement have reciprocal connections that inhibit each other. Therefore, injury to one of these areas might result in the disinhibition of intact parts of this system, intensifying those behaviors mediated/ processed by the intact regions (see Harciarek et al., 2012). For example, when performing the line bisections, some patients with right frontal-subcortical lesions have ipsilateral neglect (for review see: Heilman et al., 2012). One of the reasons they may present with ipsilateral neglect is that the right frontal injury disinhibits the posterior regions of the right hemisphere. As a result, such patients may be hyperattentive, with a spatial bias toward the contralesional (left) portion of the line (Harciarek et al., 2012; Kim et al., 1999).

There are also mutual interhemispheric inhibitions between the right and left hemispheres (Kinsbourne, 1970). Therefore, in patients with unilateral spatial neglect, injury to the posterior regions of the right hemisphere may lead to the disinhibition of the intact region of the left hemisphere. Further, this increase in the activation of the left temporoparietal cortex may lead to a rightward attentional bias. Hence, the injury of the right frontal lobe may result in disinhibition of the left frontal lobe, 
which may produce an avoidance response to right-sided stimuli. As an effect, these patients may orient their attention further to the left side.

To assess differences caused by focal attention, a compound line bisection task may be used. When performing this task, participants are presented with lines that contain two unequal segments, with one that is shorter and wider than another (Falchook et al., 2015; Mosquera et al., 2018; Shuren et al., 1997). To bisect the entire line participants must engage the global aspect of visual attention, so that both segments are attended and perceived as one line. However, when healthy participants attempt to allocate global attention to bisect the entire compound line (global condition), they have a propensity to deviate toward the longer segment (Shuren et al., 1997). The distraction of attention toward the longer line segment may occur because a participant cannot fully disengage their focal attention from the longer segment of the line (Falchook et al., 2015). Further, in healthy middle-aged adults this deviation is greater when the longer segment is on the left than on the right side of the line. This asymmetrical global distraction might be related to the right hemisphere's dominance in mediating global attention and allocating attention leftward (Mosquera et al., 2018).

In addition, in the focal condition participants are instructed to bisect only the one segment of the compound line. In this condition, when allocating focal attention to the longer segment, healthy middle-aged participants are more distracted when the longer segment is presented on the right and the smaller segment is on the left (Mosquera et al., 2018). This result is consistent with prior studies, which have revealed that, whereas the left hemisphere mediates focal attention, the right hemisphere mediates global attention (Reuter-Lorenz et al., 1990). Thus, the right hemisphere's global attention may be more likely to be activated by left-sided stimuli (for review see Heilman et al., 2012 ).

This study was designed to better characterize the ability of ESRD patients receiving hemodialysis to allocate their spatial attention. Specifically, we wanted to learn if the previously described increase in left attentional spatial bias seen in dialyzed patients (see Mańkowska et al., 2017) is related to the activation of the right parietal lobe attentional network that allocates attention toward the left hemispace or impairment of the right frontal network that mediates the disengagement from left-sided stimuli. Therefore, if the left sided attentional bias is due to the right parietal lobe attentional network activation, we expect significantly larger left-sided bias in global and focal conditions in the group of patients (right parietal lobe dysfunction is a greater contributor to deviation than the right fronto-subcortical dysfunction). As attempting to perform segment bisection of a compound line is a task that requires greater allocation of focal attention than a global bisection, healthy and ESRD participants are expected to be more distracted when the segment 
to be bisected is on the right side of the compound line (seen as a greater bias toward the left-sided shorter segment). In the left-sided focal bisection condition (longer segment on left, shorter segment on right), we expect that patients receiving hemodialysis would perform their bisections more accurately than healthy controls, likely owing to either a lateralized role of the frontal lobe in attentional disengagement (see Posner \& Petersen, 1990) and/or left hemisphere dominance in focal attention (see Reuter-Lorenz et al., 1990). Thus, this study investigated the spatial bias of dialyzed patients when selectively allocating horizontal global and focal spatial attention.

\section{METHOD}

\section{Participants}

Nineteen non-demented ESRD patients receiving hemodialysis (HD) and 21 healthy controls (HC) were the participants of this study (see Table 1). Eligible individuals were enrolled if they were between 21 and 65 years of age. Further, participants had no malignancies or clinically evident cerebrovascular disease as reflected by neurological deficits, and had no uncontrolled hypertension, diabetes and/or anemia, mental retardation, psychiatric disorders, psychoactive drug treatment (e.g., benzodiazepines), dementia, or alcohol abuse. Additionally, participants who had clinically relevant visual or hearing difficulties, as well as another major organ failure (e.g., end-stage liver disease), were not included.

On the day of testing, the mood of all participants was assessed using the Polish adaptation of Zigmond and Snaith's Hospital Anxiety and Depression Scale (HADS; Majkowicz, 1994). None of the participants had a clinically meaningful score indicating the presence of depression or/and anxiety (see Table 1). All participants declared good disposition, no sleep deprivation, or fatigue.

All dialyzed patients had estimated glomerular filtration rate (eGFR) $<15 \mathrm{ml} /$ $\min / 1.73 \mathrm{~m}^{2}$ (stage 5 of chronic kidney disease), calculated with the widely used 4-variable equation, and had received at least 1 year of dialysis.

Patients with ESRD were recruited from the Department of Nephrology, Transplantology and Internal Medicine, Medical University of Gdańsk. All control participants had no history of nephrological problems (mean eGFR $>90 \mathrm{ml} / \mathrm{min} / 1.73 \mathrm{~m}^{2}$ ), were citizens of Gdańsk, and were subjected to the same exclusion criteria as the participants who were being dialyzed. 


\section{Table 1}

Demographic and Clinical Group Characteristics

\begin{tabular}{|c|c|c|c|}
\hline \multirow{2}{*}{ Variable } & \multicolumn{3}{|c|}{ Group } \\
\hline & $\begin{array}{l}\text { Dialyzed patients } \\
\qquad(n=19)\end{array}$ & $\begin{array}{l}\text { Matched controls } \\
\qquad(n=21)\end{array}$ & $p$ \\
\hline Mean age $\pm S D$ & $46.13 \pm 9.40$ & $47.32 \pm 12.37$ & .88 \\
\hline Mean years of education $\pm S D$ & $13.45 \pm 2.30$ & $14.62 \pm 3.07$ & .37 \\
\hline $\operatorname{MMSE} \pm S D$ & $28.58 \pm 1.44$ & $29.08 \pm 0.78$ & .16 \\
\hline $\operatorname{HADS}$ Anxiety $\pm S D$ & $3.46 \pm 2.04$ & $3.58 \pm 2.48$ & .86 \\
\hline HADS Depression $\pm S D$ & $3.50 \pm 2.93$ & $2.38 \pm 2.48$ & .25 \\
\hline Sex, K:M & & & .77 \\
\hline $\begin{array}{l}\text { Mean duration of kidney disease } \\
\text { (years) } \pm S D\end{array}$ & $16.75 \pm 15.11$ & NA & NA \\
\hline Mean time on dialysis (months) $\pm S D$ & $35.31 \pm 23.95$ & NA & NA \\
\hline Mean $\mathrm{Kt} / \mathrm{V} \pm S D$ & $1.62 \pm 0.31$ & NA & NA \\
\hline $\begin{array}{l}\text { Mean blood urea nitrogen (BUN) } \\
(\mathrm{mg} / \mathrm{dl}) \pm S D\end{array}$ & $52.94 \pm 12.78$ & $14.62 \pm 2.51$ & .00 \\
\hline Mean creatinine $(\mathrm{mg} / \mathrm{dl}) \pm S D$ & $8.64 \pm 2.04$ & $0.83 \pm 0.11$ & .00 \\
\hline Mean albumin $(\mathrm{g} / \mathrm{l}) \pm S D$ & $3.90 \pm 0.30$ & $4.63 \pm 0.20$ & .19 \\
\hline Mean hemoglobin $(\mathrm{g} / \mathrm{dl}) \pm S D$ & $11.22 \pm 1.32$ & $14.64 \pm 1.29$ & .00 \\
\hline
\end{tabular}

MMSE—Mini-Mental Status Examination; HADS—Hospital Anxiety and Depression Scale; Kt/V—number used to quantify hemodialysis treatment adequacy.

\section{Materials and Procedure}

Participants attempted to bisect a series of horizontal lines composed of two segments of unequal length and width. The wider shorter segment was placed in either the right or left end of these compound lines. The participants were asked to bisect either the longer segment of these lines (focal attention condition) (Figure 1) or the entire line (global attention condition). Participants performed these tests in a randomized order. The procedure was the same as used in a study by Falchook et al. (2015) as well as Mosquera et al. (2018). 


\section{Figure 1}

The Line to be Bisected in the Segment Line Bisection Task

\section{Global Horizontal Line Bisection Task}

The following two types of lines were presented in random order and, when performing tests, the participants were asked to bisect the entire lines: 1) compound lines with the $16 \mathrm{~cm}$ longer segment to the right of the $8 \mathrm{~cm}$ shorter segment, and 2) compound lines with the $16 \mathrm{~cm}$ longer segment to the left of the $8 \mathrm{~cm}$ shorter segment. In each of these testing conditions, there were 6 lines, and in all conditions, the full line length was $24 \mathrm{~cm}$. Both healthy controls and dialyzed patients were asked to place a mark on the center of the entire 6 lines for these two types of lines. This global horizontal line bisection task was used to test the ability of these two groups of participants to resist distraction by allocating focal attention to the long line segment when they were attempting to allocate global attention to bisect the entire compound line.

\section{Focal Horizontal Line Segment Bisection Task}

In this line bisection condition, participants attempted to bisect the longer segment of a compound line. For 6 trials, the $16 \mathrm{~cm}$ longer segment was presented to the right of the $8 \mathrm{~cm}$ shorter segment, and for 6 trials the $16 \mathrm{~cm}$ longer segment was presented to the left of the $8 \mathrm{~cm}$ shorter segment. For this focal attentional task, all participants were asked to mark the center of the longer segment.

\section{Testing Procedures}

During both the global and focal conditions, participants were seated at a table and instructed to attempt the bisection by using their right hand and making a mark with a pen at the midpoint. Participants were sequentially presented with sheets of paper $(30 \times 21 \mathrm{~cm}$; A4 format $)$ that contained one compound line. These sheets of paper were consecutively placed one at a time directly in front of the participant 
in a specially prepared white frame $(61 \times 70 \mathrm{~cm})$ placed approximately $50 \mathrm{~cm}$ $( \pm 4 \mathrm{~cm})$ in front of the participant's face. During the task, participants received no feedback on their performance. After the participant attempted to bisect the line, the sheet of paper was removed and numbered, and then a new sheet of paper was placed on the frame. This continued until the participant completed all bisections. Deviation from the to-be-bisected midpoint of each line was measured to the nearest millimeter. Deviations to the right of the to-be-bisected midpoint were designated as positive, while leftward deviations were designated as negative. The results were summed for each participant, and an algebraic mean was calculated.

The Research Ethics Committee at the Institute of Psychology (Gdańsk, Poland) approved the experimental protocol of the study. Before testing, each participant signed the informed consent form, and all declared general well-being on the day of testing. After experimental procedures, all participants received 100 Polish zloty, roughly equivalent to US $\$ 25$.

\section{Statistical Analysis}

We used the Statistical Package for the Social Sciences (SPSS) version 27.0 for descriptive statistical analyses. A repeated measures ANOVA was used for the assessment of the distractibility of attention during focal and global conditions. Multiple comparisons correction was implemented using Bonferroni correction. To compare the patients' performance with that of the control group, we used independent t-tests. The effect sizes in ANOVA $\left(\eta^{2}\right)$ were computed using the procedure implemented in SPSS, whereas estimates of Cohen's d were calculated using means, sample sizes and correlations. We set two-tailed statistical significance at $p<.05$.

\section{RESULTS}

\section{Focal Condition}

A one-sample $t$-test used to compare performance in the focal condition (bisect the longer segment) with the true midpoint value $(=0)$ revealed that both groups deviated their bisections leftwards when the longer segment was on the right ( $\mathrm{HC} p<.001 ; \mathrm{HD} p<.001)$, and these groups did not differ from each other in this condition ( $t=-0.41 ; p=.68)$. By comparison, when the longer segment was on the left, healthy controls deviated their bisections of the longer segment significantly 
rightwards $(p<.001)$. However, the patients receiving dialysis did not reveal a significant rightward bias $(p=.31)$ (see Figure 2). Further, in this condition, healthy controls deviated their bisection significantly more rightwards than did the patients $(t=2.51 ; p=.017 ; d=0.71)$.

\section{Figure 2}

Mean Magnitude of Horizontal Bias in Four Conditions of Segment Line Bisection Task in Healthy Participants and Hemodialyzed Patients

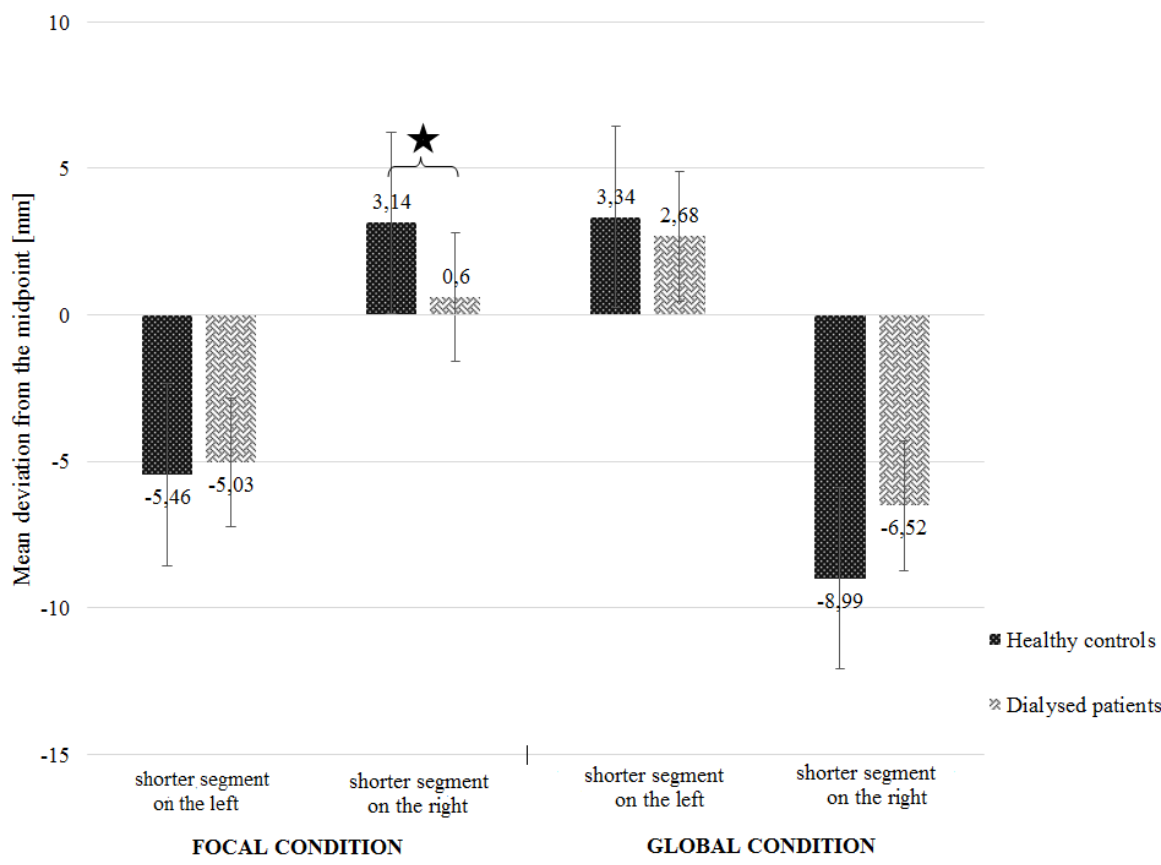

\section{Global Condition}

A one-sample t-test against true midpoint value $(=0)$ revealed that in the global line bisection condition (bisection of the entire line) when the longer segment was on the right side, both groups deviated their bisections significantly to the right (HC $p=.05$; HD $p=.02$ ) (see Figure 2). When the longer segment was on the left, participants deviated their bisections significantly to the left ( $\mathrm{HC} p<.001$; $\mathrm{HD} p<.001)$. Also, there was no group difference in the global condition, regardless of whether the shorter segment was on the left $(t=0.24 ; p=.81)$ or on the right $(t=-1.03 ; p=.31)$. 


\section{Distractibility of Global and Focal Visuospatial Attention}

In addition to investigating if the allocation of focal attention to a line segment is distracted by global attention allocated to the entire line (see above), we wanted to learn whether there are right-left distraction asymmetries when allocating focal or global attention. Thus, we conducted $2 \times 2 \times 2$ repeated measures analysis of variance (ANOVA) with the side of the shorter segment (right vs. left) and condition (global vs. focal) as within-subject factors, and group (patients vs. controls) as a between-subjects factor. However, since leftward deviations were designated as negative (see Methods section), and our analyses showed that the leftward bias was seen in both groups only in the focal condition with a shorter segment on the left as well as for the global condition with a shorter segment on the right, before running the repeated measure ANOVA we multiplied algebraic means for each participant in these two conditions by -1 .

The ANOVA revealed no group effect $\left(F(1,38)=1.46 ; p=.23 ; \eta_{\mathrm{p}}{ }^{2}=.037\right)$, nor interaction $\left(F(1,38)=0.013 ; p=.91 ; \eta_{\mathrm{p}}{ }^{2}<.00\right)$. However, a main effect of the condition emerged $\left(F(1,38)=34.20 ; p<.001 ; \eta_{\mathrm{p}}{ }^{2}=.47\right)$.

\section{Figure 3}

The Relation Between the Side of the Shorter Segment, the Attentional Condition (Global vs. Focal) and Group (Healthy vs. Hemodialyzed)

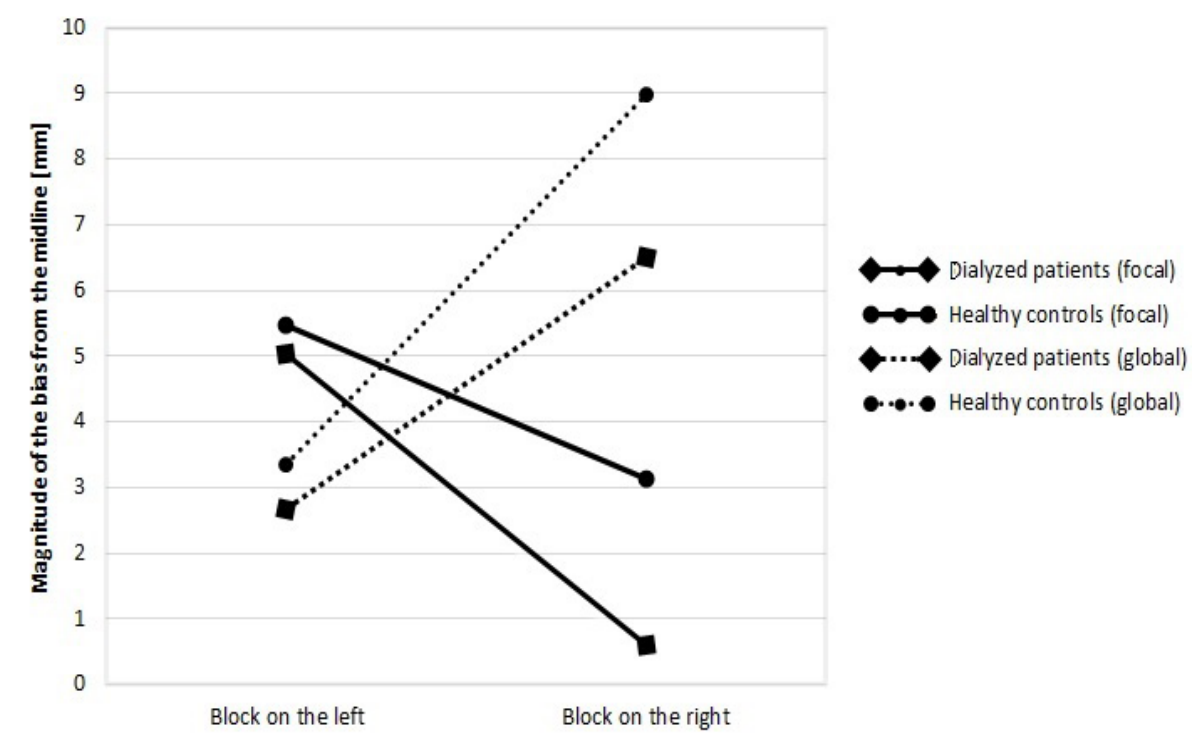


This study was designed to test if there is a difference between HD patients and healthy controls in their ability to disengage attention. Thus, despite the fact that ANOVA has not revealed a significant group effect, we have decided to perform a specific post-hoc analysis to test this postulate (Hsu, 1996). Post-hoc testing was completed using t-test for dependent variables, and were conducted separately for each group. This analysis revealed that in the global condition both patients, $t(18)=-2.37 ; p=.03 ; d=0.55$, and control participants, $t(20)=-3.84 ; p<.001$; $d=0.71$ were more distracted when the longer segment was on the left than on the right. In comparison, in the focal condition, patients receiving dialysis were more distracted when the longer segment was on the right than on the left side, $t(18)=-4.89 ; p<.001 ; d=1.77$. Similarly, control participants deviated their attempted bisections more when the longer segment was presented on the right side, $t(20)=-2.39 ; p=.03 ; d=0.62$ (see Figure 3$)$.

\section{DISCUSSION}

Overall, the results of the present study revealed that both groups significantly deviated their bisections to the left, both in the global condition with the longer segment on the left and in the focal condition with the longer segment on the right. Further, in the global condition with the longer segment on the right both groups deviated their bisections to the right, whereas rightward bias was not present in the focal condition when the longer segment was on the left. Hence, although there was a lack of group differences in the global conditions (where there is no need to disengage from a portion of the stimulus), a significant group difference emerged in the focal condition that requires a participant to disengage his/her attention from the shorter segment. Therefore together, these results provide support for the left hemispatial disengagement hypothesis, likely owing to the frontal-subcortical dysfunction.

When allocating focal attention to the longer segment of the compound line, both dialyzed patients with ESRD and healthy controls were more distracted when the longer segment was on the right than on the left. In contrast, in the global condition, both groups of participants were more distracted when the longer segment of this compound was on the left side. Although the exact reason for these effects is not entirely known, these results might be related to the right hemispheric dominance in mediating global attention as well as in allocating attention to the left hemispace (Heilman \& Van Den Abell, 1980; Pardo et al., 1991; Mosquera et al., 2018). 
However, in the focal condition of the present study, healthy controls deviated their bisection significantly more rightwards than did the patients when the shorter segment was on the right. Thus, this result suggests that the mechanism of the visuospatial attentional changes seen in patients undergoing hemodialysis seems similar to that of the ipsilesional neglect observed in patients with right frontal-subcortical lesions (Bonato et al., 2019; Harciarek et al., 2012; Kim et al., 1999; Sacchetti et al., 2015; Williamson et al., 2018). Specifically, this result from the focal condition of this study is consistent with the right hemisphere approach-avoidance theory proposed by Denny-Brown and Chambers (1958) that posits that, within the right hemisphere, the injury to the frontal lobe releases the approach-related behaviors that increase the allocation of attention to the contralateral portion of the line. Therefore, a dysfunction of our patients' right-frontal network, as posited by previous behavioral and neuroimaging studies (Harciarek et al., 2016; Mańkowska et al., 2017; Michałowski et al., 2016; Pereira et al., 2005), might have disinhibited the right parietal lobe associated with contralateral approach-related tendencies, resulting in more accurate performance of HD patients.

Alternatively, a chronic kidney disease shares many characteristics with the population of older adults. For example, compared to age-matched individuals, ESRD patients have higher prevalence of cardiovascular disease, anemia, diabetes, slowing and fatigue - similarly to the population of the elderly adults (Kurella Tamura et al., 2016; Michałowski et al., 2016; Murray, 2009). Thus, similarly like in the population of older adults, in ESRD there might be a decrease in asymmetrical brain activity during cognitive tasks (Cabeza, 2002), so called the hemispheric asymmetry reduction in older adults (HAROLD) phenomena. The HAROLD model proposes that with aging the brain activity during cognitive performance tends to become less lateralized and more widely distributed (Dolcos et al., 2002; Mańkowska et al., 2019). Support for the HAROLD postulate comes from studies of patients who have experienced strokes of the right hemisphere that result in left hemispatial neglect (Corbetta et al., 2005). Over time, patients who show improvement of neglect, reveal an increase in symmetrical hemisphere activation (Corbetta et al., 2005). Also, when bisecting the 16-cm right-sided segment of the 24-cm compound line, older adults are significantly more accurate than middle-aged adults (Mosquera et al., 2018). In addition, similar evidence supporting the HAROLD model comes from studies using the Posner stimulus-reaction time paradigm, where the valid trials are preceded by a cueing stimulus, providing information as to the side of space where the imperative stimulus will appear. This cueing stimulus induces activation of the contralateral hemisphere (Fan et al., 2002; Posner \& Petersen, 1990). Since this paradigm requires a person to attend to a focal area, the participants performing this task might be more likely to use the focal attentional system mediated by the left hemisphere (Bultitude 
\& Aimola Davies, 2006). Also, in this task younger individuals responded faster to left than right-sided imperative stimuli (effect congruent with the pseudoneglect seen in line bisection task). In contrast, older participants did not reveal a right-left asymmetry to imperative stimuli (Mańkowska et al., 2019).

The right hemisphere appears to be dominant in mediating arousal and activating the autonomic nervous system (Barnett et al., 2010; Wang et al., 2018). Several studies have noted that hemodialysis is associated with fatigue, generalized slowing, decreased cortical arousal (Harciarek et al., 2016; Michałowski et al., 2016; see also Stuss et al., 2005). Along this line, Bowen and colleagues (1999) suggested that the spatial attentional bias seen in individuals with ESRD receiving dialysis could be influenced by factors such as fatigue with reduced arousal. Hence, it is possible that the more accurate performance of hemodialyzed participants during the compound line bisection task might also have resulted from the decreased cortical arousal, likely owing to the right hemisphere structural changes frequently reported in this population (see Pereira et al., 2005).

In this study we used a compound line bisection task which, as many other visuospatial tasks, may be influenced by non-spatial parameters, such as eye movements, mood or other factors that have been shown to influence line bisection performance (Jewell \& McCourt, 2000). Indeed, despite our groups were demographically matched as well as they were matched in terms of anxiety and depression symptoms, we have not explicitly controlled for all the possible factors that might have contributed to the performance of our participants. Thus, although such factors should be considered when designing future experiments, this study still suggests the reduction in hemispheric asymmetry with the renal disease and hemodialysis.

In summary, patients with dialysis and demographically matched healthy controls showed similar patterns (directions) of their attentional bias. Specifically, in the global condition with longer segment on the left as well as in the focal condition with the longer segment on the right both groups deviated their bisections leftwards. Hence, this finding is consistent with prior research demonstrating that healthy people typically present with so called pseudoneglect (leftward attentional bias). Further, in the focal condition with the longer segment on the left and the global condition with the longer segment on the right patients receiving dialysis as well as healthy controls also demonstrated a similar attentional bias, although this time it was toward the right side. However, ESRD patients treated with hemodialysis were more accurate than controls in the focal condition with the longer segment on the left, suggesting differences in disengaging from the right-sided shorter segment. Though not statistically different in all conditions, patients were generally more accurate in their spatial judgments than healthy controls. There may be several phenomena contributing to these results. For example, in healthy older people, pseudoneglect 
diminishes and further, healthy older people are more accurate in both tasks that elicit leftward biases and tasks that elicit rightward biases (Williamson et al., 2018). Thus, it may be that patients with ESRD are more similar to older adults, potentially due to the disease/treatment-related accelerated brain aging. Further, the results of this study might be understood in light of fronto-subcortical dysfunction frequently reported in dialyzed population. Future research is necessary to both characterize potential changes in symmetry of task demand-based responses in patients with ESRD compared with healthy controls, as well as corroboration and replication of focal bias differences with other indicators of fronto-subcortical dysfunction.

\section{CRediT Author Statement}

ALEKSANDRA MAŃKOwSKA (70\%): conceptualization, methodology, software, validation, formal analysis, resources, writing (original draft), supervision, writing (review and editing).

KenNeth M. HeILman (7\%): conceptualization, supervision, writing (review and editing).

John B. Williamson (7\%): writing (review and editing).

BOGDAN BIEDUNKIEWICZ (3\%): project administration, resources.

Alicja DęBSKa-Ślızień (3\%): project administration, resources.

Michal HaRCiAREK (10\%): conceptualization, supervision, writing (review and editing).

\section{REFERENCES}

Barnett, N. P., Apodaca, T. R., Magill, M., Colby, S. M., Gwaltney, C., Rohsenow, D. J., \& Monti, P. M. (2010). Moderators and mediators of two brief interventions for alcohol in the emergency department. Addiction (Abingdon, England), 105(3), 452-465. https://doi.org/10.1111/j.13600443.2009.02814.x

Bonato, M., Romeo, Z., Blini, E., Pitteri, M., Durgoni, E., Passarini, L., Meneghello, F., Zorzi, M., \& Anderson, B. (2019). Ipsilesional impairments of visual awareness after right-hemispheric stroke. Frontiers in Psychology, 10, 1-11. https://doi.org/10.3389/fpsyg.2019.00697

Bowen, A., McKenna, K., \& Tallis, R. C. (1999). Reasons for variability in the reported rate of occurrence of unilateral spatial neglect after stroke. Stroke, 30(6), 1196-1202. https://doi. org/10.1161/01.STR.30.6.1196

Bowers, D., \& Heilman, K. M. (1980). Pseudoneglect: Effects of hemispace on a tactile line bisection task. Neuropsychologia, 18(4-5), 491-498. 
Bultitude, J. H., \& Aimola Davies, A. M. (2006). Putting attention on the line: Investigating the activation—orientation hypothesis of pseudoneglect. Neuropsychologia, 44(10), 1849-1858. https://doi.org/10.1016/j.neuropsychologia.2006.03.001

Cabeza, R. (2002). Hemispheric asymmetry reduction in older adults: The HAROLD model. Psychology and Aging, 17(1), 85-100.

Corbetta, M., Kincade, M. J., Lewis, C., Snyder, A. Z., \& Sapir, A. (2005). Neural basis and recovery of spatial attention deficits in spatial neglect. Nature Neuroscience, 8,1603 . http://dx.doi. org/10.1038/nn1574

Denny-Brown, D., \& Chambers, R. A. (1958). The parietal lobe and behavior. Association for Research in Nervous and Mental Disease, 36, 35-117.

Dixit, A., Dhawan, S., Raizada, A., Yadav, A., Vaney, N., \& Kalra, O. P. (2013). Attention and information processing in end stage renal disease and effect of hemodialysis: A bedside study. Renal Failure, 35(9), 1246-1250. https://doi.org/http://dx.doi.org/10.3109/0886022X.2013.819768

Dolcos, F., Rice, H. J., \& Cabeza, R. (2002). Hemispheric asymmetry and aging: Right hemisphere decline or asymmetry reduction. Neuroscience and Biobehavioral Reviews, 7634(July 2016), 819-825. https://doi.org/10.1016/S0149-7634(02)00068-4

Falchook, A. D., Salazar, L., Neal, D., Kesayan, T., Williamson, J. B., Malaty, I. A., McFarland, N. R., Okun, M. S., Rodriguez, R. L., Wagle Shukla, A., \& Heilman, K. M. (2015). Global attentional neglect of segmented lines in Parkinson's disease. Neurocase, 21(4), 501-508. https://doi.org/ 10.1080/13554794.2014.942671

Fan, J., McCandliss, B. D., Sommer, T., Raz, A., \& Posner, M. I. (2002). Testing the efficiency and independence of attentional networks. Journal of Cognitive Neuroscience, 14(3), 340-347. https:// doi.org/10.1162/089892902317361886

Harciarek, M., Michałowski, J., Biedunkiewicz, B., Williamson, J., Dębska-Ślizień, A., Rutkowski, B., \& Heilman, K. M. (2016). Disorders of the anterior attentional-intentional system in patients with end stage renal disease: Evidence from reaction time studies. Brain and Cognition, 107, 1-9. https://doi.org/10.1016/j.bandc.2016.05.005

Harciarek, M., Williamson, J. B., Burtis, B., Haque, S., \& Heilman, K. M. (2012). Ipsilateral neglect from a subcortical lesion. Cognitive And Behavioral Neurology, 25(1), 42-49. https://doi. org/10.1097/WNN.0b013e3182491465

Heilman, K. M., \& Valenstein, E. (1979). Mechanisms underlying hemispatial neglect. Annals of Neurology, 5(2), 166-170. https://doi.org/10.1002/ana.410050210

Heilman, K. M., \& Valenstein, E. (2003). Clinical-neuropsychology, Fourth Edition. European Journal of Neurology, 10(5), 606. https://doi.org/10.1046/j.1468-1331.2003.00655.x

Heilman, K. M., \& Valenstein, E. (2012). Clinical neuropsychology. New York: Oxford University Press.

Heilman, K. M., \& Van Den Abell, T. (1980). Right hemisphere dominance for attention: The mechanism underlying hemispheric asymmetries of inattention (neglect). Neurology, 30(3), 327-330.

Jewell, G., \& McCourt, M. E. (2000). Pseudoneglect: A review and meta-analysis of performance factors in line bisection tasks. Neuropsychologia, 38(1), 93-110. https://doi.org/10.1016/S00283932(99)00045-7

Kim, M., Na, D. L., Kim, G. M., Adair, J. C., Lee, K. H., \& Heilman, K. M. (1999). Ipsilesional neglect: Behavioural and anatomical features. Journal of Neurology, Neurosurgery \& Psychiatry, 67(1), 35-38. https://doi.org/10.1136/jnnp.67.1.35

Kinsbourne, M. (1970). The cerebral basis of lateral asymmetries in attention. Acta Psychologica, 33, 193-201. 
Kurella Tamura, M., Vittinghoff, E., Yang, J., Go, A. S., Seliger, S. L., Kusek, J. W., Lash, J., Cohen, D. L., Simon, J., Batuman, V., Ordonez, J., Makos, G., \& Yaffe, K. (2016). Anemia and risk for cognitive decline in chronic kidney disease. BMC Nephrology, 17(13), 1-7. https://doi.org/10.1186/s12882-016-0226-6

Kwon, S. E., \& Heilman, K. M. (1991). Ipsilateral neglect in a patient following a unilateral frontal lesion. Neurology, 41(12), 2001-2004. https://doi.org/10.1212/wnl.41.12.2001

Lynch, J. C. (1980). The functional organization of posterior parietal association cortex. Behavioral and Brain Sciences, 3(4), 485-499.

Majkowicz, M. (1994). Skala HAD [The Hospital Anxiety and Depression Scale-HAD]. In K. de Walden-Galuszko \& M. Majkowicz (Eds.), Jakość życia w chorobie nowotworowej [Quality of life in malignant disease] (pp. 153-158). Gdańsk: Wydawnictwo Uniwersytetu Gdańskiego.

Mańkowska, A., Heilman, K. M., Williamson, J. B., Biedunkiewicz, B., Dębska-Ślizień, A., \& Harciarek, M. (2017). Leftward bias of visual attention in patients with end-stage renal disease receiving dialysis: A neglected phenomenon. Cognitive and Behavioral Neurology, 30(4), 176-181.

Mańkowska, A., Heilman, K. M., Williamson, J. B., \& Harciarek, M. (2019). Age-related changes in the allocation of spatially directed focal attention. Aging, Neuropsychology and Cognition, 24(10), 1121-1124. https://doi.org/10.1017/S1355617718000620

Michałowski, J. M., Harciarek, M., Biedunkiewicz, B., Williamson, J., Debska-Ślizień, A., Rutkowski, B., \& Heilman, K. M. (2016). Slowing with end-stage renal disease: Attentive but unprepared to act. International Journal of Psychophysiology, 106, 30-38. https://doi.org/10.1016/j.ijpsycho.2016.06.002

Mosquera, D. M., Lamb, D. G., Garcia, A. M., Rodriguez, J. A., Correa, L. N., Salazar, L., Schwartz, Z. J., Cohen, R. A., Falchook, A. D., \& Heilman, K. M. (2018). Asymmetrical distractibility of global and focal visuospatial attention during segmental and total compound line bisections. Neuropsychology, 32(7), 843-849. https://doi.org/10.1037/neu0000455

Murray, A. M. (2009). Editorial: The brain and the kidney connection: A model of accelerated vascular cognitive impairment. Neurology, 73(12), 916-917. https://doi.org/10.1212/ WNL.0b013e3181b99a2e

Pardo, J. V., Fox, P. T., \& Raichle, M. E. (1991). Localization of a human system for sustained attention by positron emission tomography. Nature, 349(6304), 61-64. https://doi.org/10.1038/349061a0

Pereira, A. A., Weiner, D. E., Scott, T., \& Sarnak, M. J. (2005). Cognitive function in dialysis patients. American Journal of Kidney Diseases, 45(3), 448-462. https://doi.org/10.1053/j.ajkd.2004.10.024

Posner, M. I. (1980). Orienting of attention. Quarterly Journal of Experimental Psychology, 32, 3-25. https://doi.org/10.1080/00335558008248231

Posner, M. I., \& Petersen, S. E. (1990). The attention system of the human brain. Annual Review of Neuroscience, 13(1), 25-42. https://doi.org/10.1146/annurev.ne.13.030190.000325

Reuter-Lorenz, P., Kinsbourne, M., \& Moscovitch, M. (1990). Hemispheric control of spatial attention. Brain and Cognition, 266(190), 240-266. http://www.sciencedirect.com/science/article/ pii/027826269090018J

Robertson, L. C., Lamb, M. R., \& Knight, R. T. (1988). Effects of lesions of temporal-parietal junction on perceptual and attentional processing in humans. The Journal of Neuroscience: The Official Journal of the Society for Neuroscience, 8(10), 3757-3769. https://doi.org/10.1101/lm.54702

Sacchetti, D. L., Goedert, K. M., Foundas, A. L., \& Barrett, A. M. (2015). Ipsilesional neglect: Behavioral and anatomical correlates. Neuropsychology, 29(2), 183-190. https://doi.org/10.1037/ neu0000122 
Shuren, J. E., Jacobs, D. H., \& Heilman, K. M. (1997). The influence of center of mass effect on the distribution of spatial attention in the vertical and horizontal dimensions. Brain and Cognition, 34(2), 293-300. https://doi.org/https://doi.org/10.1006/brcg.1997.0918

Stuss, D. T., Alexander, M. P., Shallice, T., Picton, T. W., Binns, M. A., Macdonald, R., Borowiec, A., \& Katz, D. I. (2005). Multiple frontal systems controlling response speed. Neuropsychologia, 43(3), 396-417. https://doi.org/10.1016/j.neuropsychologia.2004.06.010

Wang, C., Burtis, D. B., Ding, M., Mo, J., Williamson, J. B., \& Heilman, K. M. (2018). The effects of left and right monocular viewing on hemispheric activation. Journal of Clinical and Experimental Neuropsychology, 40(2), 198-204. https://doi.org/10.1080/13803395.2017.1332169

Williamson, J. B., Lamb, D. G., Burtis, D. B., Haque, S., M. Zilli, E., Kesayan, T., Harciarek, M., \& Heilman, K. M. (2018). Right hemispatial ipsilesional neglect with chronic right hemisphere strokes. Journal of Clinical and Experimental Neuropsychology, 40(4), 347-356. https://doi.org /10.1080/13803395.2017.1347606

Wright, D., Makin, A. D. J., \& Bertamini, M. (2015). Right-lateralized alpha desynchronization during regularity discrimination: Hemispheric specialization or directed spatial attention? Psychophysiology, 52(5), 638-647. https://doi.org/10.1111/psyp.12399 